\title{
Coordinate Measuring Machine Retrofit and Technological Upgradation
}

\author{
S. Ashokkumar, S. Sathiyaraj, R. Mahesh, Blesson Achankunju, Karthik R, Jean Joseph
}

\begin{abstract}
Planned To Import Axis Motors and Air Bearing From U.S. •Planned To Import 5axis Probe Head, Probe Head \& Machine Controller, 5 Axis Measurement Software From U.K. -Machine Axis X-900mm, Y-1200mm, Z-800mm, A-115 ${ }^{\circ}$ To $115^{\circ}$, B- Infinity Position. Being Five Axis Technologies We Can Minimize the Measurement Time By 70\%, So Throughput Of The Machine Can Be Increased. •Being Five Axis Technologies We Can Rotate The Probe Head With Infinite Positions Which Can Minimize The Stylus Calibration \& Increases Machine Accuracy. •CMM Retrofit, Technological Upgradation \& Calibration Cost Will Come Around 80 Lakhs.
\end{abstract}

Keywords : 5 Axis CMM Technology, 5 Axis machine \& Probe Controller, 5 axis measurement software \& CMM Calibration.

\section{INTRODUCTION}

$\mathrm{M}_{\mathrm{a}}$ achine was sunk in 12 feet rain water during 2015 Chennai VARDHA Cyclone \& all the machine elements like Air bearing, Axis motors, encoder, Reader head, Controller, Software was in damaged condition.10 Years Old CMM. -Machine made In Germany[1]. •3 Axis Machine X-900mm Y-1200mm Z-800mm. •Machine Affected in Chennai December 2015 Flood \& Machine Under Breakdown Condition[2]. •Axis motors, Air Bearing, Encoders, Controller, Probe Head, Measurement Software Can't Be Repaired and Used[3]. Figure 1 shows the CMM machine.

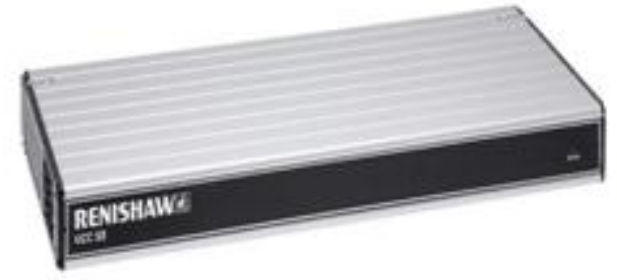

a)

Revised Manuscript Received on December 16, 2019

* Correspondence Author

S.Ashokkumar *,- Assistant Professor Department of Mechanical Engineering Aarupadai Veedu Institute of Technology Vinayaka Mission Research Foundation, Chennai, India.Email: ashokkumar@avit.ac.in

S.Sathiyaraj, Assistant Professor Department of Mechanical Engineering Aarupadai Veedu Institute of Technology, Vinayaka Mission Research Foundation, Chennai, India. Email: sathiyaraj@avit.ac.in

R.Mahesh , Assistant Professor Department of Mechanical Engineering Aarupadai Veedu Institute of Technology, Vinayaka Mission Research Foundation,Chennai,India. Email: mahesh@avit.ac.in

BlessonAchankunju, Karthik R, Jean Joseph, Department of Mechanical Engineering Aarupadai Veedu Institute of Technology,Vinayaka Mission Research Foundation, Chennai, India.

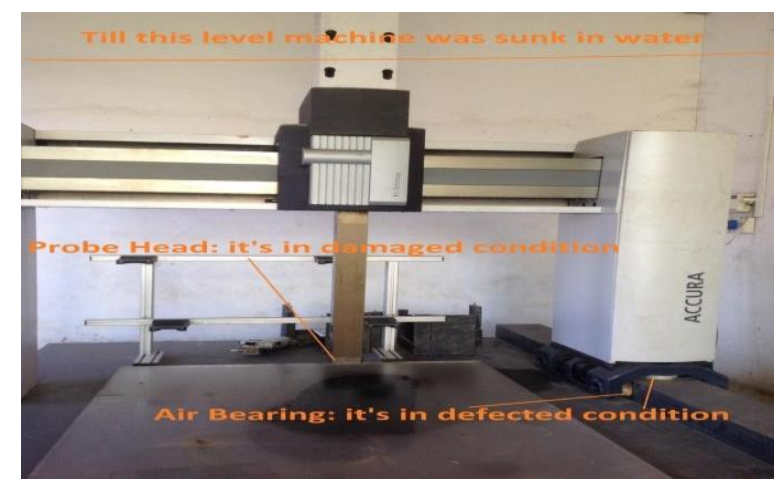

b)

Fig. 1.a)\&b)CMM machine.

\section{MATERIALS AND METHODS}

At the core of any Renishaw MCM refurbishment, interfacing with all sensors of Renishaw and supplying contact with metrological technology, is the array of UCC standard CMM controls. The UCC S5 consists of a control unit in a 19-inch rack[4]. It is linked by an Ethernet connection to the CMM host computer and by external cable interfaces to the CMM.

Three axes CMM control (acceptance of interpreted digital signals and three axis engine control signals) CMM control

- Accepting emergency stop and air pressure input signs, collision sensors, electronic SPA systems, amplifier faults and all direction internal and external movement.

- limit switches

- Consider two general input signals uncommitted and produce one uncommitted general output signal.interface REVO-2

- Fund the servo control amplifier directly from Renishaw SPA3

- Renishaw and RS232 (Mitutoyo) TEC systems are directly supported provide a $+24 \mathrm{~V}$ supply for use by the CMM switches

- UCC S5 supports SPA3 joysticks with MCUlite-2, MCU5, MCU5-2, MCU W and MCU W-2.

- This guide gives information on physical installation, system connections and communications, as well as assistance in fault finding duringThe installation of the UCC S5.

The UCC S5 is a high power, multi-axis, universal CMM controller that provides improved measurement efficiency using creative and advanced motion control algorithms. 
For the revolutionary 5-axis System Renscan5TM UCC1TM provides the powerful platform. Superior computer error mapping is offered in an open format, which allows users to re-calibrate themselves when temperature correction is also possible.

- Compliant for I++ DME

- Proof of future-future Renishaw sensors to be integrated with UCC controllers will be designed.

\section{REVO 2 - 5 AXIS PROBE HEAD KIT}

The dynamic measuring head and probe system REVO-2 is designed to maximize measurement throughput whilst maintaining high system accuracy.

REVO2 is the only scan system for CMMs that simultaneously checks the movement of three machines and two head axes while collecting data from the workpiece using its 2D and 3D range of tactile samples, surfacture measurement sensor, and now contactless. Vision probe too.The head's design incorporates sophisticated laser measurement and electrical signal transmission technology for precise work piece measurement at extremely high rates of data capture. The 5-axis control system prevents unnecessary machine movement dynamic errors as most testing is done by the measuring eye. Because the head is much lightweight and flexible than the CMM, changes in the component structure can be followed quickly. without introducing large dynamic errors. The REVO-2 multi-sensor system is managed by the I++ DME compliant UCC server interface.Probe head show in the figure 3.

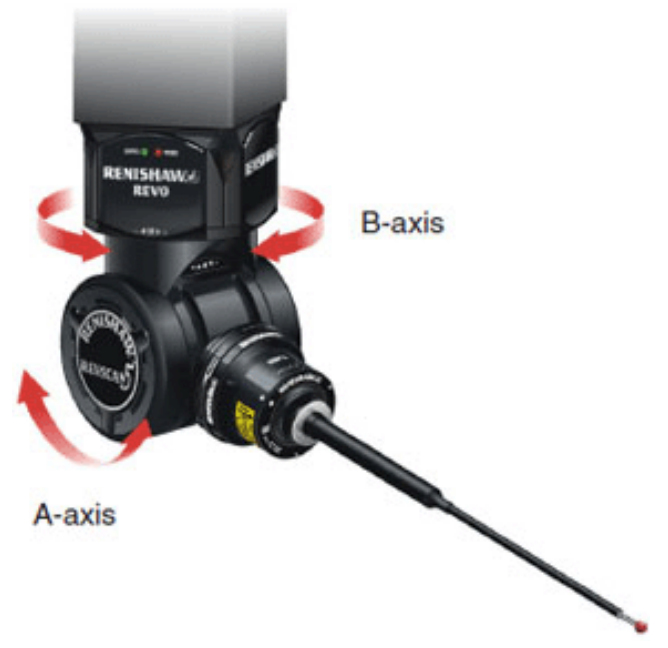

Fig. 2.Probe head .

- RSP2 is a dedicated lightweight REVO-2 sensor that can measure 2D (x,y) and 3D tactile (x, y, z) devices. The RSP2 is commonly fitted with a number of different type holders with different lengths of at least $115 \mathrm{~mm}$ and a maximum scope of $500 \mathrm{~mm}$.

- The RSP works with the favorable technologies from Renishaw, designed specifically to reduce the forces of scanning and reduce stylus wear. The UCC controller manages the type of stylus that can be used with RSP2, ensuring that optimal metrology performance is achieved.

\section{ENCODER TONIC READHEAD \& SCALE}

The Renishaw Series is a new generation of super compact encoders designed for highly dynamic precision movement systems that provide a wide variety of demanding industries with higher precision, speed and reliability. In addition to the proven RSLM stainless steel scale, high accurate RELM RELM RELM Read heads are complemented by the latest developments of the RGSZ20 golden tape scale, REXM ultra-exact angular encoder, and FASTRACKTM / RTLC bidirectional optical references invar scale and Rotating rings from RESM. Readheads have third generation filtering optics, designed to reduce even the noise level (Jitter). This further increases adaptive signal handling, Auto Gain Control and Auto Offset Control are included.For maximum performance and high dust resistance.

The effect is a low SDE, resulting in better regulation of velocity for enhanced scan strength and position stability. A detachable analog or digital interface is also available in the form of a powerful, compact connector that is up to $10 \mathrm{~m}$ from the readhead. The software supports $1 \mathrm{~nm}$ digital interpolation of clocked inputs for maximum performance speed performance at all resolutions for industry-standard controllers. The encoder is shown in the figure 4.

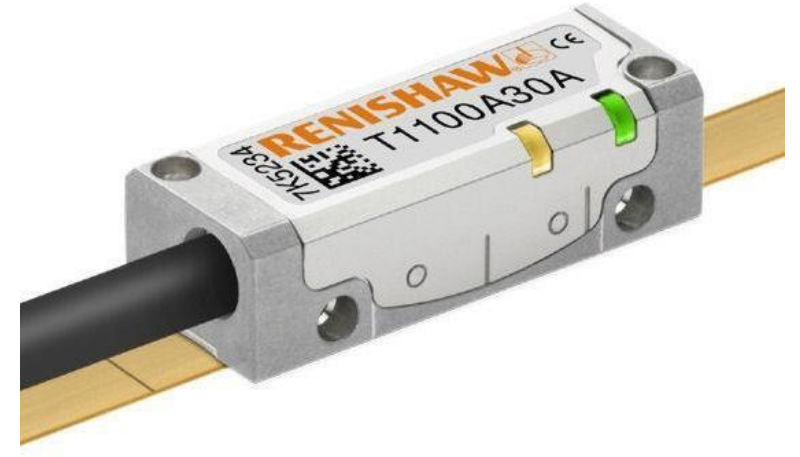

Fig. 3. Encoder .

\section{MCU5 JoYSTICK}

The MCU is designed shown in the figure 5 in an ergonomically designed enclosure for use with the UCC controllers which allows for mounting of the manual or table. A large LCD screen gives status data and communicates with the system metrology.

MCU is suitable for:

- Regulation the CMM axis movement

- Index the motorized head

- Operate the rotary table

- Operate as a computer mouse

Has a device menu that permits operating machine navigation.

Sharing the design and characteristics of the MCU1, the MCU5 incorporates a STOP button. It allows the CMM to quickly stop without deactivating and is ideal for use with the $\mathrm{REVO}^{\mathrm{TM}}$ system.

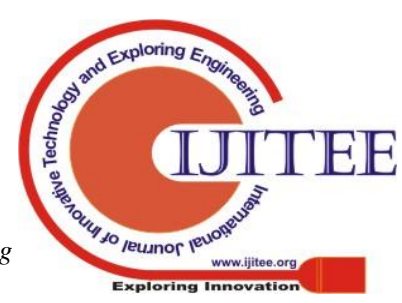




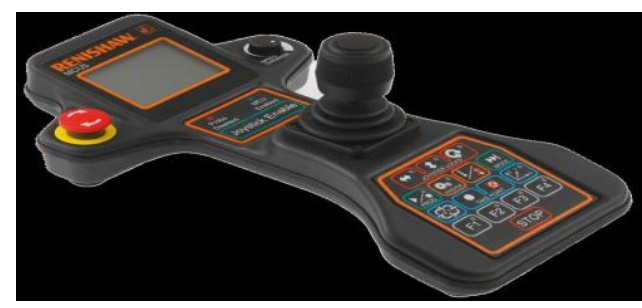

Fig. 4.MCU5 Joystick .

\section{XYZ -AXIS AIR BEARING}

An aero-static or aerodynamic bearing shown in the figure 6 is the rolling stock used to provide a low friction load-lasting interface between the surfaces with a thin film of pressurized gas. Both faces are not affected by typical friction, tear, particulate matter and lubricant handling problems associated with the bearing and offer significant advantages in precision positioning as well as in high-speed applications, such as a lack of backlash and static friction.

The aerodynamic covers are differentiated by establishing the air cushion through the relative movement between the static and the moving parts, and Aerostatic bearings where the stress is applied externally.

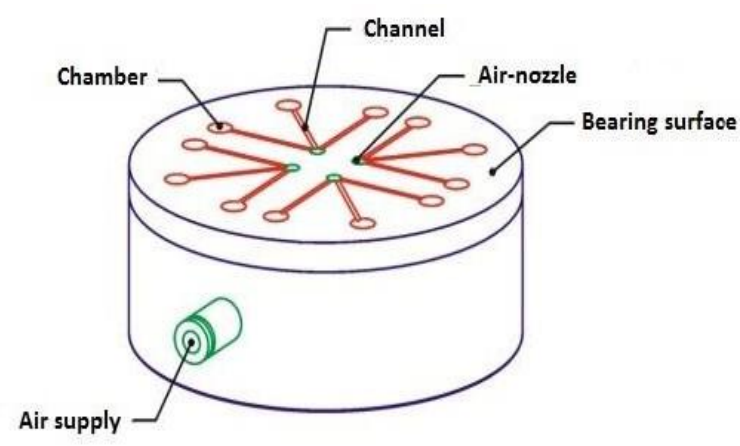

Fig. 5. Air Bearing .

Air rollers are mostly used in devices for calculation and treatment of machines and high-speed machinery (spindles and turbomachinery of a small scale).

Air nozzle bearing with chambers and canals The air compressed into a few relatively large pins (diameter 0.1 $0.5 \mathrm{~mm}$ ) in the bearing gap with a traditional single nozzle aerostatic rollers. The use of gas thus requires only a certain degree of flexibility to change the characteristics of the bearing (force, moments, bearing surface, height of gap bearing and damping). Nonetheless, aero-state bearing makers take positive strategies, even with some nozzles, to permit a clear gas pressure. This causes the dead volumes (uncompressible and therefore low air pressures) of these bearings.

This dead density is indeed very detrimental to the structure of the gas bearing and induces auto-exciting vibrations.

\section{CMM CALIBRATION}

Keep your CMM accurate with the Renishaw Calibration and Certification service:

- Certified by UKAS to ISO 17025

- Full calibration that complies with ISO 10360-2

- Full calibration of your REVO system (if installed)

- Update of your CMM error map

- Update of your CMM controller software

Renishaw provides full copies of your CMM configuration files and error map to you as well as maintain a copy in your history file on Renishaw's secure worldwide network database Figure 7 shows the UKAS Logo. Calibration of your $\mathrm{CMM}$ will be completed as part of your CMM retrofit

- Certified by UKAS to ISO 17025

- Full calibration that complies with ISO 10360-2.

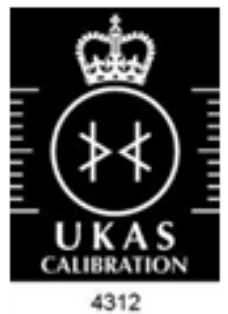

Fig. 6.UKAS Logo .

\section{RESULT AND DISCUSSION}

Case Story 1: Housing component -Current Scenario

- Required 6-8 stylus and 2-3 stylus adaptor for one component Since probe head is fixed one, different combinations are required for effective inspection.

- Significant inspection time loss due to frequent stylus changing moves of the CMM

- Required 2 set up for complete inspection

- Non-productive long preparation time for different stylus combinations and set up since each component requires specific stylus combination.

- Considerable calibration time ( 45 min/day) which directly impacts on overall machine utilization and its efficiency.

- Surface finish cannot be done on CMM itself and outside of CMM also it is a challenge for bigger size components.

- Even though running $24 \mathrm{hrs}$, limited machine speed and fixed head cannot suffice required inspection need in terms of volume.

- CMM bottleneck causes compromise on $100 \%$ inspection

- Total inspection time for one component $\sim 35-40$ minutes

Advantages of 5 Axis on-Front Housing component

- Required only one stylus for complete inspection of component Since Revo is 5 axis infinite solution, we need minimum stylus combinations

- Complete inspection in One set up

- Considerable reduction in non-productive tool preparation time

- Improved inspection time with minimum tool changing moves

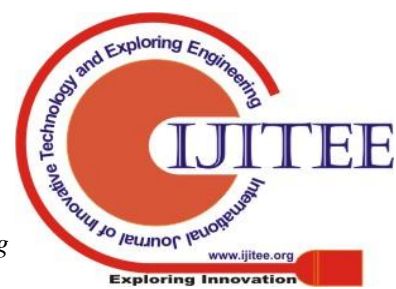


- Minimum calibration time ( 17 min/day) and maximum inspection time

- Surface finish can be done on CMM itself even for bigger size of components.

- Maximum utilization of machine due to revolutionary infinite positioning and incredibly faster cycle time

- Total inspection time for one complete component is JUST 13 minutes.

Case Story 2: Cylinder Head Valve Seat Measurement

The measurements 12 valve seats 36 scans on valve guides (3 per guide),Figure 8 shows the Probe head during calibration and figure 9 shows the comparison chart.

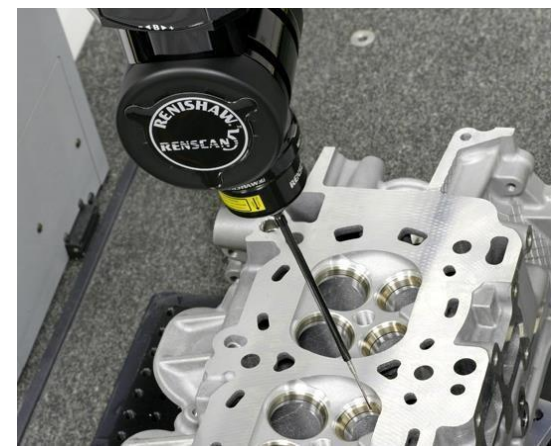

Fig. 7.Probe head during calibration .

Before:

3 -axis scanning at $15 \mathrm{~mm} / \mathrm{sec}$

measurement time $-29 \mathrm{~min} 13 \mathrm{sec}$

After:

$\mathrm{REVO}^{\mathrm{TM}}$ at $400 \mathrm{~mm} / \mathrm{sec} \& 50 \mathrm{~mm} / \mathrm{sec}$

measurement time $-3 \mathrm{~min} 42 \mathrm{sec}$

$690 \%$ improvement!

Time to measure 10 parts

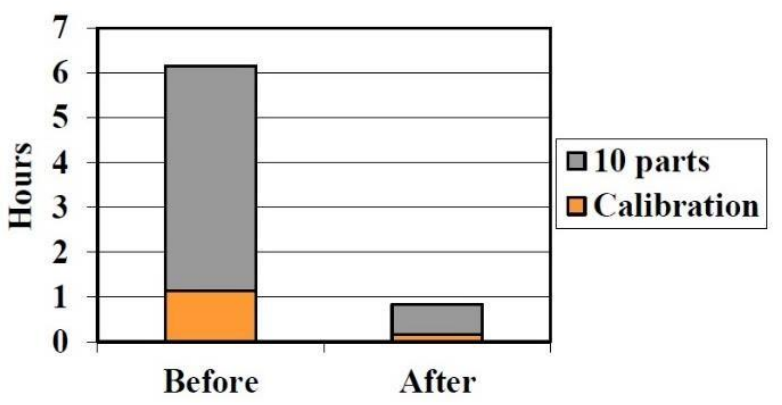

Fig. 8.Comparison Chart .

\section{CONCLUSION}

- Innovative Technology

- Rapid inspection throughput

- Proven robustness for in-line inspection

- Enhanced performance of existing CMM.
4. A.Aravindkumar,"CFD ANALYSIS OF GAS FLOW BEHAVIOR IN VARIOUS ECONOMIZER DUCT", International Journal of MC Square Scientific Research,Vol.6, No.1 Nov 2014,pp.61-65.

\section{AUTHORS PROFILE}

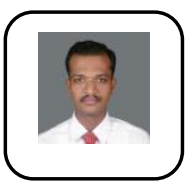

S. Ashokkumar, Assistant Professor, Department of Mechanical Engineering, Aarupadai Veedu Institute of Technology Vinayaka Mission Research Foundation,Chennai,India. ashokkumar@avit.ac.in.

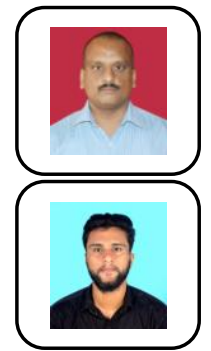

S.Sathiyaraj, Assistant Professor, Department of Mechanical Engineering, Aarupadai Veedu Institute of Technology Vinayaka Mission, Research Foundation sathiyaraj@avit.ac.in

R.Mahesh, Assistant Professor, Mechanical Department, Aarupadai Veedu Institute Of Technology, Vinayaka Mission's Research Foundation, Deemed To Be University. Having 13 years of experience. Life member in ISTE and ENFUSE.

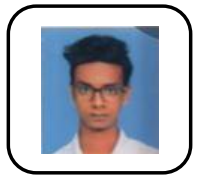

BlessonAchankunju, UG Student, Mechanical Department, Aarupadai Veedu Institute Of Technology, Vinayaka Mission's Research Foundation, Deemed To Be University.

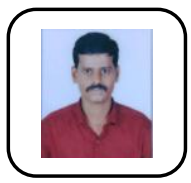

Karthik, UG Student Mechanical Department, AarupadaiVeedu Institute Of Technology, Vinayaka Mission's Research Foundation, Deemed To Be University

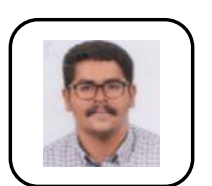

Jean Joseph, UG Student Mechanical Department AarupadaiVeedu Institute Of Technology, Vinayaka Mission's Research Foundation, Deemed To Be University.

\section{REFERENCES}

1. Renishaw- 5 Axis Probe head, Controller \& Software- Datasheet [online].

2. Air bearing, Servo motors datasheets from manufacturer[online].

3. CMM laser calibration as per UKAS to ISO 17025[online]. 